\title{
Effects of Physical Exercises on Peripheral Neuropathy Sensation in Patients with Type 2 Diabetes: A Literature Review
}

\author{
Laode Saltar $^{1 *}$ and Junaiti Sahar ${ }^{2}$ \\ 1Department of Community Health Nursing, School of Nursing, Mandala Waluya School of Health Sciences, \\ Indonesia; \\ saltarlaode@yahoo.com \\ 2Department of Community Health Nursing, Faculty of Nursing, University of Indonesia \\ junaitisahar@gmail.com \\ *Correspondence: saltarlaode@yahoo.com \\ Type of the Paper (Article)
}

Received: July 27, 2020; Accepted: August 17, 2020; Published: September 5, 2020

https://doi.org/10.29253/achnr.2020.21145

\begin{abstract}
Background - The most common complication in patients with type 2 diabetes is peripheral neuropathy. Physical exercise is one of the effective Prevention and treatment strategies of peripheral neuropathy in type 2 diabetes. Aims and objectives - The aim of this review articles is to describe the effectiveness of physical exercise on peripheral neuropathy sensation in patients with type 2 diabetes. Methods - A number of databases such as Science Direct, Springer Link, ProQuest, EBSCOhost, and Google Scholar were searched for relevant articles using keywords such as "type 2 diabetes", AND "peripheral neuropathy sensation" OR "diabetes peripheral neuropathy" AND "physical exercises" OR "aerobic exercises" OR "resistance exercise". All types of articles were included for the study, such as systematic reviews, randomized controlled trial, quasi-experiment, literature review, and pilot study with the range 2015-2020. Only articles in English are included in this review. Results - Of the 11 articles found, 9 articles showed that physical exercise had a direct effect on improving foot sensation in diabetic peripheral neuropathy patients, while the other 2 articles had an indirect effect on improving symptoms of peripheral neuropathy. Four types of physical exercise that are practiced in interventions are: aerobic exercise, resistance exercise, balance and flexibility exercise and a combination of two or more types of exercise. Physical exercise from low to moderate intensity has a positive effect on increasing foot sensation in patients with type 2 diabetes peripheral neuropathy. Conclusions - This review emphasizes the effect of physical exercise on peripheral neuropathic sensation in type 2 DM patients and strengthens the evidence that low and moderate-intensity exercise are beneficial to reduce peripheral neuropathy symptoms. Further research on the effectiveness of home and community-based physical exercise to reduce symptoms of peripheral neuropathy is necessary.
\end{abstract}

Keywords: physical exercises; peripheral neuropathy sensation; type 2 diabetes; literature review

\section{Introduction}

The most common complication in diabetes mellitus (DM) patients is peripheral neuropathy (Jember et al., 2017) and also become the main cause of ulceration and amputation of the foot 
(Seyedizadeh et al., 2020). Global estimates, the prevalence of peripheral diabetic neuropathy (DPN) ranges from 9.6 - 88.7\% of the DM population (Jember et al., 2017). It is known that the global prevalence of DM cases at the age of 18 years and over increased from 4.7\% in 1980 to $8.5 \%$ in 2014 (WHO, 2016). As many as 30-50\% of DM patients reported experiencing complications of DPN (Tesfaye, 2019; Hershey, 2016). The prevalence of DPN based on the Michigan Neuropathy Screening Instrument (MNSI) measurement in Jordan is 39.5\% (Khawaja et al., 2018), while in Ethiopia through a cross-sectional study there were cases of peripheral neuropathy of $52.2 \%$ (192 of 368 DM patients) (Jember et al., 2017). In Indonesia, information related to the risk of DM complications and DFU incidence is still inadequate. A study states that the main complications of DM in Indonesia are neuropathy (13\% - 78\%), microvascular complications $(16 \%-53 \%)$ and diabetic foot ulcer ranging from $7.3 \%-24 \%$ (Abrar et al., 2019). Neuropathy is the most complication of DM in RSUP Dr. Cipto Mangunkusumo (RSCM) amounted to 54\% in 2011 (Kemenkes RI, 2014).

Some studies have shown the benefits of physical exercise in preventing complications of DM, improving glycemic control and reducing neuropathic pain (Hangping et al., 2019; Lee et al., 2017; Kluding et al., 2012). Exercise and physical activity are non-pharmacological interventions to improve peripheral sensory function and outcomes related to DM (Matos et al., 2018). A systematic review shows that lifestyle interventions are effective in improving neuropathy symptoms (Zilliox \& Russell, 2019). Physical exercise is an effective modality therapy for type 2 DM patients (Balducci et al., 2006). Physical exercise is physical activity that is carried out in a planned and structured manner with the aim of improving health and or fitness (Sigal et al., 2018). This literature review aims to describe the effectiveness of physical exercise in improving foot sensation for peripheral neuropathy in type $2 \mathrm{DM}$ patients.

\section{Literature Review}

Diabetic peripheral neuropathy is defined as the presence of symptoms and / or signs of peripheral nerve damage after exclusion of other causes in DM patients (Hershey, 2016; Bruschi et al., 2017). The main clinical symptoms of DPN are loss of sensation or numbness. Other signs and symptoms include tingling, burning or stabbing pain, pain when walking, a hot or cold sensation in the legs (Tesfaye, 2019). Factors that are significantly related to the incidence of DPN include: poor glycemic control, unemployment (lack of physical activity), cardiovascular disease, duration of suffering from diabetes, dyslipidemia, hypertension, smoking, and being overweight (Alramadan et al., 2019; Hershey, 2016; Khawaja et al., 2018).

The cause of neuropathy cannot be explained with certainty (Hershey, 2016), but a prolonged hyperglycemia condition that triggers an increase in the levels of Advanced Glycation End (AGE) and Protein Kinase C (PKC) products is the main contributor to the metabolic changes that produce DPN (Akter, 2019). Hyperglycemia causes a combination of axonal injury, insulin resistance, toxic adiposity, endothelial injury, and microvascular dysfunction resulting in nerve ischemia which contributes to the development of DPN. Progressive loss of nerve fibers results in the development of diabetic peripheral neuropathy, with symptoms of paresthesia and pain. Loss of nerve fibers begins with small nerve fibers, then involves large nerve fibers as the disease progresses. In addition, contributors to the development of DPN come from changes in vascular factors, neurostructural mechanisms, and metabolic interactions (Hershey, 2016).

Well-known instruments for measuring or evaluating the presence of peripheral neuropathy are The Michigan Neuropathy Screening Instrument (MNSI), with a sensitivity of $80 \%$ and specificity of $95 \%$ and the Semmes-Weinstein Monofilament Examination (SWME). Semmes-Weinstein monofilament (SWME) examination as the cheapest and safest DPN screening method (Farhat \& Yezback, 2016; Navarro-peternella \& Teston, 2019).

\section{Methodology}

The literature search focused on "physical exercise and sensation of peripheral neuropathy in type 2 DM patients". A number of databases such as Science Direct, Springer Link, ProQuest, EBSCOhost, and Google Scholar were searched for relevant articles. Literature search using keywords such as "type 2 diabetes", AND "peripheral neuropathy sensation" OR "diabetes peripheral neuropathy" AND "physical exercises" OR "aerobic exercises" OR "resistance exercise". All types of articles were included for the 
study, such as systematic reviews, randomized controlled trial, quasi-experiment, literature review, and pilot study with the range 2015-2020. Only articles in English are included in this review.

\section{Results}

Based on the keywords entered in the five databases, 1.262 articles appeared and then were screened for titles, abstracts, repetition of articles and article content. The search results only found 11 articles discussing physical exercise in relation to sensation of peripheral neuropathy (Table 1). From these 11 articles, analysis was carried out and it can be concluded that there are two effects that physical exercise has on diabetic peripheral neuropathy, namely a direct positive effect on neuropathy (Dixit et al., 2019; Kanchanasamut \& Pensri, 2017; Matos et al., 2018; Nadi et al., 2017; Navarro-peternella \& Teston, 2019; Zilliox \& Russell, 2019; Johnson \& Takemoto, 2019; Stubbs Jr et al., 2019; Gholami et al., 2020) and indirect effects on neuropathic sensation (Gholami et al., 2018; Seyedizadeh et al., 2020).

Types of Physical Exercise

Four types of physical exercise were practiced in the research intervention, such as: aerobic exercise, resistance exercise, balance and flexibility training, and a combination of two or more types of exercise. Aerobic exercise is physical activity that is carried out with rhythmic, structured and continuous movements involving large muscles for at least 10 minutes per session. Examples of aerobic exercise are walking, mini trampoline exercises, cycling, swimming and jogging (Sigal et al., 2018). Aerobic exercise is divided into three levels, namely low, medium and high intensity. Low intensity ranges from $60-70 \%$ Maximum Heart Rate (HRM) or 1.1 - 2.9 METs (Siomos et al., 2017). Medium intensity ranges from 70 $80 \%$ HRM or 3 - 5.9 METs and high intensity $\geq 80 \%$ HRM or $\geq 6$ METs (Johnson \& Takemoto, 2019; Sigal et al., 2018). Resistance training is repetitive exercise using additional weights, weight lifting machines, resistance bands, or body weight alone to increase muscle strength and/ or endurance (Sigal et al., 2018). Examples of resistance training are chest press, wide-grip lat pulldown, barbell curl, lying triceps press, leg extension, lying leg curls, sit-up, and push-up using body building equipment. Examples of resistance training are chest press, wide-grip lat pulldown, barbell curl, lying triceps press, leg extensions, lying leg curls, sit-ups, and push-ups using bodybuilding equipment. Flexibility training is a form of activity, such as stretching the lower back or hamstrings, that increases the ability of the joint to move through its various movements. Balance exercises are exercises that are only intended to improve balance. Combination exercises are combined movements that combine several exercises such as tai chi and yoga (Sigal et al., 2018).

\section{Measurement of Sensation of Diabetic Peripheral Neuropathy}

Decreased sensory foot diabetic peripheral neuropathy is indicated by a decrease in the perception of pressure and vibration in the feet (Kanchanasamut \& Pensri, 2017). Measurements of peripheral neuropathy that are frequently used are the Michigan Neuropathy Screening Instrument (MNSI) and the Semmes-Weinstein monofilament Examination (SWME).

\section{Michigan Neuropathy Screening Instrument (MNSI)}

MNSI is a validated assessment instrument. This instrument has two components, namely a history and examination questionnaire (Kanchanasamut \& Pensri, 2017; Farhat \& Yezback, 2016; Hershey, 2016). The component of the history questionnaire is about feelings in the feet which consists of 15 questions with a choice of "yes" and "no" answers. Each question is worth 1 point. A score $>7$ indicates diabetic peripheral neuropathy (Hershey, 2016). The components of the examination include appearance, ulceration, ankle reflexes, perception of vibrations in the big toe, and examination of the monofilament. Score 1 if the appearance shows deformity, dry skin and / or calluses, infection and fissure; the presence of ulceration; ankle reflex absent; vibration perception using a $128-\mathrm{Hz}$ tuning fork is absent; and the correct answer on the monofilament examination does not exist. Score 0.5 if on the first test the ankle reflex is absent and the reflex appears when using the Jendrassic maneuver; on vibration perception the examiner felt a vibration $\geq 10$ seconds longer than the patient; on monofilament examination, there are 1 to 7 correct answers. Positive for neuropathy if the score is $>2.5$ (Hershey, 2016).

\section{Semmes-Weinstein Monofilament Examination (SWME)}

Another measurement of sensory function for peripheral neuropathy is to use the SemmesWeinstein monofilament (SWME) examination as the cheapest and safest DPN screening method (Farhat 
\& Yezback, 2016; Navarro-peternella \& Teston, 2019). There are 10 measurement points on each of the right and left feet covering the big toe; the plantar aspects of the 1st, 3rd and 5th metatarsal heads; and six locations on the plantar base using $10 \mathrm{~g}$ monofilament. The measurement procedure is that the patient is asked to sit or lie down, then the soles of his feet are straightened and given a touch of nylon monofilament thread by being placed on the soles of the feet and bent slightly so that the nylon puts pressure on the soles of the feet. The pressure is held for up to 2 seconds and then the examiner instructs the patient to say "yes" if he has felt the monofilament sensation. The patient is asked to close his eyes during the test. The examiner also needs to use a fake test, which is to ask the patient if he feels the monofilament when it is not done. A decrease in perception is indicated by loss of sensation at least one assessment site (Navarro-peternella \& Teston, 2019; Ahn \& Song, 2012; Feldman et al., 2020; Kanchanasamut \& Pensri, 2017).

\section{Effect of Physical Exercise}

\section{Direct positive effect on sensation of diabetic peripheral neuropathy}

Research on the effectiveness of aerobic exercise in increasing sensation of peripheral neuropathy has shown strong evidence. A randomized controlled trial (RCT) study with a single blind parallel group approach to 84 DM patients who were divided into a study group of 37 people and a control group of 47 people. The study was conducted at a tertiary university hospital in India which aims to determine the effect of moderate intensity aerobic exercise for 8 weeks on the threshold of vibration sensation perception (VPT) in peripheral neuropathy of type 2 diabetes. Vibration sensation in diabetic peripheral neuropathy was measured using a Biothesiometer (QST Devices). In the study group, patients were given education on the prevention and management of foot problems in type 2 diabetes through posters and given diabetes diet instructions by nutritionists. Moderate intensity treadmill exercise is done 3 to 6 days a week, with a duration of 150 minutes to a maximum of 360 minutes per week. Heart rate for sports training is carried out in the range of $40 \%-60 \%$ of the heart rate reserve (HRR). The results showed that there was a significant difference in the vibration perception threshold (VPT) at 3 points (thumb, medial malleoli, first metatarsal phalanx), for both lower limbs between the control and study groups (df1, df2 $=1.63 ; \mathrm{F}=8.56 ; \mathrm{p}<0.001$ ). This shows that moderate intensity aerobic exercise (treadmill) has a positive effect in increasing the sensation of peripheral nerve vibrations in type $2 \mathrm{DM}$ patients with peripheral neuropathy (Dixit et al., 2019). The same study by Stubbs Jr et al (2019) to determine the effectiveness of aerobic structured programs, isokinetic strength, or a combination of aerobic-isokinetic strength training interventions in changing peripheral nerve function in diabetic patients who experience glycemic controlled symmetric polyneuropathy. The study involved 38 DM patients, divided into 11 aerobic exercise patients, 10 isokinetic strength training patients, 8 aerobic-isokinetic strength patients and 9 sedentary control patients. Exercises are performed 3 times a week for 12 weeks. A 10-minute warm-up consisting of stretching and flexibility exercises starts all training sessions. The results show that aerobic exercise improves peripheral sensory nerve function.

Other supporting research is the study of Kanchanasamut \& Pensri (2017) on 21 DM neuropathy patients. The intervention was divided into 11 patients in the exercise group and 10 patients in the control group, which was carried out at home for 8 weeks with an intensity of 5 times a week. The intervention was in the form of foot care education and resistance training with a mini-trampoline, which is an activity in the form of a program containing a variety of strong weight-bearing activities such as jumping and hopping. The results showed an increase in somatosensory perception in both legs, where the number of subjects who experienced a decrease in pressure and vibration perceptions in the exercise group significantly decreased at week 8 and $20(p=0.008-0.031)$. Apart from aerobic exercise, resistance training has also been shown to improve peripheral neuropathy. A systematic review by Johnson \& Takemoto (2019) suggests that low-intensity resistance training reduces pain disruption in daily activities, lowers pain thresholds, and reduces neuropathy symptoms.

Combination exercises, which are combinations of several types of exercise, have been shown to increase the sensation of neuropathy. Clinical trial research with a sample of $30 \mathrm{DM}$ patients in the form of muscle stretching exercises that were carried out actively with 3 repetitions; muscle strengthening performed passively by the therapist; and sensory exercise which is actively performed where, the exercise is done twice a week for 12 weeks in 50 minute sessions. The results showed an increase in plantar skin sensibility in the exercise group compared to the control group on the right leg (3.46 points; 95\% confidence interval CI, 3.85-9.80), left foot (3.46 points; 95\% CI, 4.06-9.76). So it can be concluded 
that cutaneous plantar sensory stimulation increases foot sensibility (Navarro-peternella \& Teston, 2019). A systematic review by Matos et al. (2018) further strengthens the benefits of physical exercise in improving peripheral neuropathy. This systematic review suggests that two studies used aerobic exercise; two studies combined aerobic, resistance and balance exercise; and two combined studies of aerobic exercise and balance using the Thai Chin Chuan method. The results of the review show that physical activity and exercise significantly increase nerve conduction velocity, peripheral sensory function and peak foot pressure distribution. Research by Gholami et al (2020) also provides evidence that cycling exercise with $50 \%-70 \%$ of heart rate reserve, carried out for $30-45$ minutes in 3 sessions / week for 12 weeks, reduces symptoms of peripheral neuropathy.

\section{Indirect effect on sensation of diabetic peripheral neuropathy}

Another RCT study of 24 female DM patients, who were divided into an exercise group and a control group in a combination aerobic and resistance exercise training program carried out for 3 sessions per week for 8 weeks was not significant in increasing upper body strength, but it was significant in increasing lower body strength. The progressive nature of peripheral neuropathy has slightly changed (Seyedizadeh et al., 2020). With the same research method, research (Gholami et al., 2018) on 24 DM peripheral neuropathies divided into 12 exercise groups, 12 control groups, where the experimental group first conducted 3 socialization sessions a week before the main intervention, then the respondents underwent aerobic exercise program for three months (walking, jogging or running on a treadmill, 3 sessions a week, 50-70\% HRR, 20-45 minutes). The results showed that the sural sensory nerve conduction velocity (NCV) in the exercise group significantly increased (from $35.2 \pm 4.3 \mathrm{~m} / \mathrm{s}$ to $37.3 \pm$ $6.2 \mathrm{~m} / \mathrm{s}$ ) compared to the control group ( $\mathrm{P}=0.007)$. Aerobic exercise has the potential to inhibit the development of PN diabetes by increasing NCV (Gholami et al., 2018).

\section{Discussion}

Physical exercise is an alternative non-pharmacological therapy that can improve glycemic control, neuropathic sensation, pain, muscle strength and quality of life for DPN patients. Types of physical exercise include aerobic, resistance, stretching, and balance exercises such as tai-chi (Ahn \& Song, 2012). Improved neuropathic sensation through an aerobic exercise program with a follow-up of 10 weeks has shown strong evidence. By increasing the cutaneous nerve fibers, plantar numbness is reduced in patients with DPN after physical exercise. This exercise can also increase the conduction velocity of the sural sensory nerves and the peroneal motor nerves. In the mini trampoline exercise the muscles of the body and lower extremities such as the knee and leg muscles are contracted, so that balance and stability of the body can be controlled (Kanchanasamut \& Pensri, 2017). Balance and resistance training in the form of active muscle stretching with a therapist combined with electrical stimulation can also increase the sensibility of the plantar skin in both feet and increase walking speed among older adults with DM2. In addition to the effect of exercise, the effect of electrical stimulation is regenerating cell and nerve function caused by hyperglycemia in diabetes (Navarro-peternella \& Teston, 2019). Improvement of pain felt in daily activities, pain threshold and neuropathic symptoms can be reduced through low intensity resistance training. In addition, an increase in the patient's quality of life and an increase in lower leg strength as a result of increased foot sensation and decreased pain and tingling symptoms can be obtained through low-intensity aerobic exercise (Johnson \& Takemoto, 2019).

Exercise has a number of beneficial effects on the body, including improving hypertension, increasing organ perfusion, reducing lipid and protein oxidation and reducing humoral inflammation (Zilliox \& Russell, 2019). Exercise intervention reduces pain and symptoms of neuropathy (Kluding et al., 2012). Systematic review by (Zilliox \& Russell, 2019) concluded that physical exercise provides little change in the progressive nature of peripheral neuropathy, therefore further research is needed involving adequate samples (Seyedizadeh et al., 2020). In contrast to the case (Stubbs Jr et al (2019), exercise is not statistically significant in improving nerve function, but exercise, regardless of type, does not worsen peripheral sensory injury or motor nerve injury in diabetic neuropathic patients (Stubbs Jr et al (2019). 
Table 1. The effectiveness of physical exercise on sensation of peripheral neuropathy in type 2 DM patients.

\begin{tabular}{|c|c|c|c|c|c|c|}
\hline Reference & Participants & Design & $\begin{array}{l}\text { Intervention and } \\
\text { type of exercise }\end{array}$ & Exercise techniques & Follow-up & Outcome on neuropathy \\
\hline $\begin{array}{l}\text { (Kanchanasamut } \\
\& \text { Pensri, 2017) }\end{array}$ & $\begin{array}{l}21 \text { patients with } \\
\text { diabetic } \\
\text { neuropathy }\end{array}$ & RCT & $\begin{array}{ll}\text { - } & \text { Foot care } \\
\text { education and } \\
\text { mini-trampoline } \\
\text { exercises } \\
\text { - } & \text { Aerobic exercise }\end{array}$ & $\begin{array}{l}\text { Powerful weight-bearing } \\
\text { activities such as jumping } \\
\text { and hopping, spot walking } \\
\text { on mini trampolines, one- } \\
\text { leg jumps and two-leg } \\
\text { alternate hops with front } \\
\text { and rear displacement. }\end{array}$ & $\begin{array}{l}\text { Five times a } \\
\text { week for } \\
\text { eight weeks }\end{array}$ & 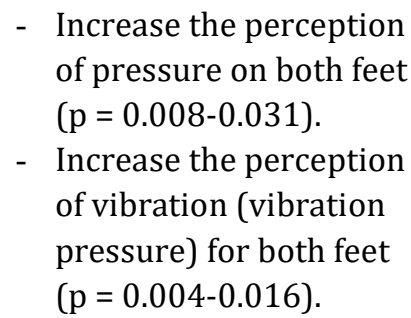 \\
\hline $\begin{array}{l}\text { (Navarro- } \\
\text { peternella \& } \\
\text { Teston, 2019) }\end{array}$ & $\begin{array}{l}30 \text { DM patients } \\
\text { aged } \geq 60 \text { years }\end{array}$ & Clinical trial & $\begin{array}{l}\text { Combination of } \\
\text { balance and } \\
\text { resistance training }\end{array}$ & $\begin{array}{l}\text { Active muscle stretching; } \\
\text { Passive muscle } \\
\text { strengthening with } \\
\text { therapists; Sensory } \\
\text { exercise }\end{array}$ & $\begin{array}{l}\text { Twice a week } \\
\text { for } 12 \text { weeks } \\
\text { in } 50 \text { minute } \\
\text { sessions }\end{array}$ & $\begin{array}{l}\text { Increases the sensibility of } \\
\text { the plantar skin on both } \\
\text { feet }\end{array}$ \\
\hline $\begin{array}{l}\text { (Dixit et al., } \\
\text { 2019) }\end{array}$ & $\begin{array}{l}37 \text { DM patients } \\
\text { in the study } \\
\text { group, } 47 \\
\text { patients in the } \\
\text { control group. }\end{array}$ & $\begin{array}{l}\text { Single blind } \\
\text { parallel } \\
\text { group RCT }\end{array}$ & $\begin{array}{l}\text { Moderate treadmill } \\
\text { exercise }\end{array}$ & $\begin{array}{l}\text { The heart rate for exercise } \\
\text { training was carried out in } \\
\text { the range of } 40 \% \text { to } 60 \% \\
\text { and heart rate reserve } \\
\text { (HRR) as an adjunct to this } \\
\text { rating of perceived exertion } \\
\text { (RPE) (scale ranging from } 6 \\
\text { to } 20 \text { ) was carried out } \\
\text { before, during, and } \\
\text { postexercise. }\end{array}$ & $\begin{array}{l}150 \text { - } 360 \\
\text { minutes per } \\
\text { week, } 3 \text { days } \\
\text { per week }\end{array}$ & $\begin{array}{l}\text { Increased vibration } \\
\text { perception threshold } \\
\text { (VPT) at } 3 \text { points (thumb, } \\
\text { medial malleoli, first } \\
\text { metatarsal phalanx) (df1, } \\
\text { df2 = 1, 63; F = 8.56; P } \\
<.001 \text { ). }\end{array}$ \\
\hline
\end{tabular}


Table 1. The effectiveness of physical exercise on sensation of peripheral neuropathy in type 2 DM patients. (continued)

\begin{tabular}{|c|c|c|c|c|c|c|}
\hline $\begin{array}{l}\text { (Seyedizadeh et } \\
\text { al., 2020) }\end{array}$ & $\begin{array}{l}24 \text { female DM } \\
\text { patients }\end{array}$ & $\mathrm{RCT}$ & $\begin{array}{l}\text { Combination of } \\
\text { aerobic and } \\
\text { resistance training }\end{array}$ & $\begin{array}{l}\text { The resistance training: } \\
\text { chest press, wide-grip lat } \\
\text { pulldown, barbell curl, } \\
\text { lying triceps press, leg } \\
\text { extension, lying leg curls, } \\
\text { sit-up, and push-up using } \\
\text { bodybuilding equipment. } \\
\text { The aerobic training: the } \\
\text { interval running with 3- } \\
\text { minute repetitions and a } \\
\text { rest time of } 30 \text { seconds. }\end{array}$ & $\begin{array}{l}3 \text { sessions } \\
\text { per week for } \\
8 \text { weeks. }\end{array}$ & $\begin{array}{l}\text { Increase lower body } \\
\text { strength. And cause minor } \\
\text { changes in the progressive } \\
\text { nature of diabetic } \\
\text { peripheral neuropathy }\end{array}$ \\
\hline $\begin{array}{l}\text { (Stubbs Jr et al., } \\
\text { 2019) }\end{array}$ & $38 \mathrm{DM}$ patients & RCT & $\begin{array}{l}\text { Combination of } \\
\text { aerobic and } \\
\text { resistance training }\end{array}$ & $\begin{array}{l}\text { Warm-up, treadmill } \\
\text { waking, isokinetic leg } \\
\text { extensions }\end{array}$ & $\begin{array}{l}3 \text { times a } \\
\text { week for } 12 \\
\text { weeks }\end{array}$ & $\begin{array}{l}\text { Improve sensory nerve } \\
\text { function }\end{array}$ \\
\hline $\begin{array}{l}\text { (Zilliox \& Russell, } \\
\text { 2019) }\end{array}$ & Twenty studies & SR & $\begin{array}{l}\text { Diet and physical } \\
\text { exercise } \\
\text { interventions }\end{array}$ & & & $\begin{array}{l}\text { Prevents the development } \\
\text { of peripheral neuropathy }\end{array}$ \\
\hline
\end{tabular}


Table 1. The effectiveness of physical exercise on sensation of peripheral neuropathy in type $2 \mathrm{DM}$ patients. (continued)

\begin{tabular}{|c|c|c|c|c|c|c|}
\hline $\begin{array}{l}\text { (C. Johnson \& } \\
\text { Takemoto, 2019) }\end{array}$ & 10 articles & $\begin{array}{l}\text { Systematic } \\
\text { review }\end{array}$ & $\begin{array}{l}\text { Aerobic training, } \\
\text { resistance training, } \\
\text { balance training }\end{array}$ & $\begin{array}{l}\text { Aerobic: walking, } \\
\text { minitrampoline } \\
\text { Resistance: weight } \\
\text { machines } \\
\text { Balance: Tai-chi, yoga }\end{array}$ & & $\begin{array}{l}\text { Low intensity exercise } \\
\text { improves leg sensation in } \\
\text { peripheral neuropathy }\end{array}$ \\
\hline $\begin{array}{l}\text { (Gholami et al., } \\
\text { 2018) }\end{array}$ & $\begin{array}{l}24 \text { volunteers } \\
\text { diagnosed with } \\
\text { diabetic PN }\end{array}$ & RCT & Aerobic exercise & $\begin{array}{l}\text { Walk, jog or run on the } \\
\text { treadmill. }\end{array}$ & $\begin{array}{l}3 \text { sessions a } \\
\text { week, } 20-45 \\
\text { minutes per } \\
\text { session for } 3 \\
\text { months }\end{array}$ & $\begin{array}{l}\text { Aerobic exercise has the } \\
\text { potential to inhibit the } \\
\text { development of PN } \\
\text { diabetes by increasing } \\
\text { NCV. More research is } \\
\text { needed on the mechanism } \\
\text { of exercise linking. }\end{array}$ \\
\hline $\begin{array}{l}\text { (Gholami et al., } \\
\text { 2020) }\end{array}$ & 31 respondents & RCT & Aerobic exercise & Cycling & 12 weeks & $\begin{array}{l}\text { Decreased neuropathic } \\
\text { symptoms from } 12.2 \pm 3.9 \\
\text { at baseline to } 7.9 \pm 2.4 \text { at } \\
\text { post-workout in the } \\
\text { experimental group }(\mathrm{t}= \\
4.346, \mathrm{P}=0.001)\end{array}$ \\
\hline 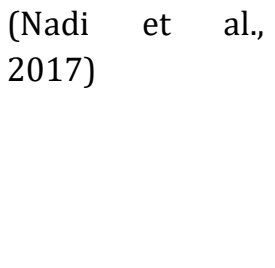 & $\begin{array}{l}81 \text { female } \\
\text { patients with } \\
\text { type } 2 \mathrm{DM}\end{array}$ & RCT & $\begin{array}{l}\text { Combination of } \\
\text { aerobic and } \\
\text { resistance exercise } \\
\text { and vitamin D } \\
\text { supplements }\end{array}$ & $\begin{array}{l}\text { Light stretches to warm up, } \\
\text { Simple aerobic exercise } \\
\text { exercises, resistance } \\
\text { training moves with } \\
\text { dumbbells and stretches for } \\
\text { cool down }\end{array}$ & $\begin{array}{l}12 \text { weeks and } \\
3 \text { sessions / } \\
\text { week and } 60 \\
\text { minutes / } \\
\text { session. }\end{array}$ & $\begin{array}{l}\text { Increased sensation in } \\
\text { numbness }(\mathrm{P}=0.001) \text {, and } \\
\text { vibration perception }(\mathrm{P}= \\
0.001)\end{array}$ \\
\hline
\end{tabular}


Physical exercise, either done alone or in combination, has a good effect on peripheral neuropathy in type 2 DM patients. Further research is needed with methods of efficient physical exercise both at home and involving groups and according to the age level of type $2 \mathrm{DM}$ patients. more than 150 minutes per week can reduce $\mathrm{HbA} 1 \mathrm{c}$ with an average change of $-0.89 \%$ compared to intervention of less than 150 minutes per week (Sigal et al., 2018). This is supported by a meta-analysis which found that supervised exercise interventions lowered HbA1c in type 2 DM patients (Umpierre et al., 2016).

Glycemic control can be improved through resistance training. So far there has not been an optimal endurance training program standard in terms of frequency, intensity, type and volume of training. The benefits of physical activity in DM patients include improving cardiorespiratory fitness, increasing strength, increasing glycemic control, lowering blood pressure and helping to lose weight (Sigal et al., 2018). Low intensity resistance training decreases the threshold for pain and neuropathic symptoms. Exercise of any kind does not worsen peripheral sensory or motor injury in patients with diabetic peripheral neuropathy (Stubbs Jr et al (2019). Physical exercise, either alone or in combination, has a good effect on peripheral neuropathy in type 2 diabetes patients. Resistance training in combination with regular aerobic exercise twice a week is effective in reducing HbA1c and body fat. Increased glycemic control prevents and reduces the development of peripheral neuropathy. However, there is no clear standard in terms of frequency, intensity, type and volume in the resistance training program (Sigal et al., 2018). After physical exercise intervention in type 2 DM patients with peripheral neuropathy, there was an improvement in HbA1c levels and neuropathy symptoms assessed using MDNS (Gholami et al., 2020). Increased glycemic control can reduce the development of nerve dysfunction and neuropathic symptoms in type 2 DM patients. Nerve dysfunction in DM is not only caused by hyperglycemia, but vascular factors are thought to be involved in the development of DPN, namely hypoxia due to blood flow disorders (Gholami et al., 2020). Therefore, many studies have investigated the conduction velocity of nerves, as they affect blood supply. This study shows that aerobic exercise has the potential to inhibit the development of PN diabetes by increasing nerve conduction velocity (NCV). The increase in NCV sural after local warming is directly related to local blood supply, but further research is needed to see the long-term impact of exercise. Improved nerve conductive function through increased NCV, especially sural sensory nerves can be achieved through 12 weeks of aerobic exercise. The sensory nerves in the lower extremities are more sensitive to hyperglycemia, so they will be more sensitive to adaptation in exercise (Gholami et al., 2020; Seyedizadeh et al., 2020).

\section{Conclusion}

This review emphasizes the effect of physical exercise on peripheral neuropathic sensation in type 2 DM patients and strengthens the evidence that low and moderate-intensity exercise are beneficial to reduce peripheral neuropathy symptoms. Further research on the effectiveness of community-based physical exercise to reduce symptoms of peripheral neuropathy is necessary.

\section{References}

Abrar, E. A., Yusuf, S., Sjattar, E. L., \& Rachmawaty, R. (2019). Development and evaluation educational videos of diabetic foot care in traditional languages to enhance knowledge of patients diagnosed with diabetes and risk for diabetic foot ulcers. Primary Care Diabetes, 1-7. https://doi.org/10.1016/j.pcd.2019.06.005

Ahn, S., \& Song, R. (2012). Effects of tai chi exercise on glucose control, neuropathy scores, balance, and quality of life in patients with type 2 diabetes and neuropathy. Journal of Alternative and Complementary Medicine, 18(12), 1172-1178. https://doi.org/10.1089/acm.2011.0690

Akter, N. (2019). Diabetic Peripheral Neuropathy: Epidemiology, Physiopathology, Diagnosis and Treatment. Delta Medical College Journal, 7(1), 35-48. https://doi.org/10.3329/dmcj.v7i1.40619

Alramadan, M. J., Magliano, D. J., Alhamrani, H. A., Alramadan, A. J., Alameer, S. M., Amin, G. M., Alkharras, W. A., Bayaseh, N. A., \& Billah, B. (2019). Lifestyle factors and macro- and micro-vascular complications among people with type 2 diabetes in Saudi Arabia. Diabetes and Metabolic Syndrome: Clinical Research and Reviews, 13(1), 484-491. https://doi.org/10.1016/j.dsx.2018.11.007

Balducci, S., Iacobellis, G., Parisi, L., Di Biase, N., Calandriello, E., Leonetti, F., \& Fallucca, F. (2006). Exercise training can modify the natural history of diabetic peripheral neuropathy. Journal of Diabetes and Its Complications, 20(4), 216-223. https://doi.org/10.1016/j.jdiacomp.2005.07.005

Dixit, S., Maiya, A., \& Shastry, B. A. (2019). Effects of Aerobic Exercise on Vibration Perception Neuropathy Population Using 3-sites Method: Threshold in Type 2 Diabetic Peripheral Single-blind Randomized Controlled Trial. 
Alternative Therapies, 25(2), 36-41.

Farhat, N. M., \& Yezback, K. L. (2016). Treatment of Diabetic Peripheral Neuropathy. Journal for Nurse Practitioners, 12(10), 660-666. https://doi.org/10.1016/j.nurpra.2016.07.030

Feldman, E. L., Callaghan, B. C., Pop-busui, R., Zochodne, D. W., Wright, D. E., Bennett, D. L., Bril, V., Russell, J. W., \& Viswanathan, V. (2020). Diabetic neuropathy. 5(1), 1-40. https://doi.org/10.1038/s41572-019-00979.Diabetic

Gholami, F., Nazari, H., \& Alimi, M. (2020). Cycle Training improves vascular function and neuropathic symptoms in patients with type 2 diabetes and peripheral neuropathy: A randomized controlled trial. Experimental Gerontology, 131(August 2019), 110799. https://doi.org/10.1016/j.exger.2019.110799

Gholami, F., Nikookheslat, S., Salekzamani, Y., Boule, N., \& Jafari, A. (2018). Effect of aerobic training on nerve conduction in men with type 2 diabetes and peripheral neuropathy: A randomized controlled trial. Neurophysiologie Clinique, 48(4), 195-202. https://doi.org/10.1016/j.neucli.2018.03.001

Hangping, Z., Xiaona, Q., Qi, Z., Qingchun, L., Na, Y., Lijin, J., Siying, L., Shuo, Z., Xiaoming, Z., Xiaoxia, L., Qian, X., \& Jaimovich, D. (2019). The impact on glycemic control through progressive resistance training with bioDensity TM in Chinese elderly patients with type 2 diabetes The PReTTy2 ( Progressive Resistance Training in Type 2 Diabetes ) Trial. 0, 5-12. https://doi.org/10.1016/j.diabres.2019.02.011

Hershey, D. S. (2016). Diabetic Peripheral Neuropathy: Evaluation and Management. The Journal for Nurse Practitioners, 13(3), 199-204.e1. https://doi.org/10.1016/j.nurpra.2016.08.034

Jember, G., Melsew, Y. A., Fisseha, B., Sany, K., Gelaw, A. Y., \& Janakiraman, B. (2017). Peripheral Sensory Neuropathy and associated factors among adult diabetes mellitus patients in Bahr Dar, Ethiopia. Journal of Diabetes and Metabolic Disorders, 16(1), 1-8. https://doi.org/10.1186/s40200-017-0295-5

Johnson, C., \& Takemoto, J. K. (2019). A review of beneficial low-intensity exercises in diabetic peripheral neuropathy patients. Journal of Pharmacy and Pharmaceutical Sciences, 22(1), 22-27. https://doi.org/10.18433/jpps30151

Kanchanasamut, W., \& Pensri, P. (2017). Effects of weight-bearing exercise on a mini-trampoline on foot mobility, plantar pressure and sensation of diabetic neuropathic feet; a preliminary study. Diabetic Foot and Ankle, 8(1). https://doi.org/10.1080/2000625X.2017.1287239

Bruschi, L., Rocha, D., Filho, E., Barboza, N., Frisanco, ...Arbex, A. (2017). Diabetes Mellitus and Diabetic Peripheral Neuropathy. Open Journal of Endocrine and Metabolic Diseases. 07(1): 12-21 DOI:10.4236/ojemd.2017.71002.

Kemenkes RI. (2014). infodatin-diabetes.pdf.

Khawaja, N., Shennar, J. A., Saleh, M., Dahbour, S. S., Khader, Y. S., \& Ajlouni, K. M. (2018). The prevalence and risk factors of peripheral neuropathy among patients with type 2 diabetes mellitus; the case of Jordan. Diabetology \& Metabolic Syndrome, 1-10. https://doi.org/10.1186/s13098-018-0309-6

Kluding, P. M., Pasnoor, M., Singh, R., \& Jernigan, S. (2012). The Effect of Exercise on Neuropathic Symptoms, Nerve Function, and Cutaneous Innervation in People with Diabetic Peripheral Neuropathy. NIH Public Access, 26(5), 424-429. https://doi.org/10.1016/j.jdiacomp.2012.05.007

Lee, J. H., Kim, D. H., \& Kim, C. K. (2017). Resistance Training for Glycemic Control, Muscular Strength, and Lean Body Mass in Old Type 2 Diabetic Patients: A Meta-Analysis. Diabetes Therapy, 8(3), 459-473. https://doi.org/10.1007/s13300-017-0258-3

Matos, M., Mendes, R., Silva, A. B., \& Sousa, N. (2018). Physical activity and exercise on diabetic foot related outcomes: A systematic review. Diabetes Research and Clinical Practice, 139(September), 81-90. https://doi.org/10.1016/j.diabres.2018.02.020

Nadi, M., Marandi, S. M., Esfarjani, F., Saleki, M., \& Mohammadi, M. (2017). The Comparison between Effects of 12 weeks Combined Training and Vitamin D Supplement on Improvement of Sensory-motor Neuropathy in type 2 Diabetic Women. Advanced Biomedical Research, 6, 55. https://doi.org/10.4103/2277-9175.205528

Navarro-peternella, F. M., \& Teston, E. F. (2019). Plantar Cutaneous Sensory Stimulation Improves Foot Sensibility and Gait Speed in Older Adults With Diabetes : A Clinical Trial. 32(12), 568-573.

Seyedizadeh, S. H., Cheragh-birjandi, S., Reza, M., \& Nia, H. (2020). The Effects of Combined Exercise Training ( Resistance-Aerobic) on Serum Kinesin and Physical Function in Type 2 Diabetes Patients with Diabetic Peripheral Neuropathy ( Randomized Controlled Trials ). 2020.

Sigal, R. J., Armstrong, M. J., Bacon, S. L., Boulé, N. G., Dasgupta, K., Kenny, G. P., \& Riddell, M. C. (2018). Physical Activity and Diabetes. Canadian Journal of Diabetes, 42, S54-S63. https://doi.org/10.1016/j.jcjd.2017.10.008

Siomos, M. Z., Andreoni, M., Buchholz, S. W., \& Dickins, K. (2017). A Guide to Physical Activity for Individuals With\&nbsp;Diabetes. TJNP: The Journal for Nurse Practitioners, 13(1), 82-88.e4. https://doi.org/10.1016/j.nurpra.2016.10.025

Stubbs Jr, E. B. S., Fisher, M. A., Miller, C. M., Jelinek, C., Butler, J., Mcburney, C., \& Collins, E. G. (2019). Randomized Controlled Trial of Physical Exercise in Diabetic Veterans With Length-Dependent Distal Symmetric Polyneuropathy.

Frontiers

in

Neuroscience,

13(February),

$1-20$. 
https://doi.org/10.3389/fnins.2019.00051

Tesfaye, S. (2019). Neuropathy in diabetes. Medicine (United Kingdom), 47(2), 92-99. https://doi.org/10.1016/j.mpmed.2018.11.009

Umpierre, D., Kramer, C. K., Leita, C. B., Gross, J. L., Ribeiro, J. P., \& Schaan, B. D. (2016). Physical Activity Advice Only or Structured With HbA 1c Levels in Type 2 Diabetes. A Systematic Review and Meta-analysis. JAMA: The Journal of the American Medical Association, 305(17), 1790-1799.

WHO. (2016). Global Report on Diabetes. In World Health Organization (Vol. 978). http://www.who.int/about/licensing/

Zilliox, L. A., \& Russell, J. W. (2019). Physical activity and dietary interventions in diabetic neuropathy : a systematic review. Clinical Autonomic Research, 29(4), 443-455. https://doi.org/10.1007/s10286-019-00607-x 